Gut, 1973, 14, 574-580

\title{
Experimental hepatic necrosis: Studies on coagulation abnormalities, plasma clearance, and organ distribution of ${ }^{125}$ I-labelled fibrinogen
}

\author{
M. O. RAKE, P. T. FLUTE, G. PANNELL, K. B. SHILKIN, AND ROGER WILLIAMS \\ From the Liver Unit and the Departments of Haematology and Morbid Anatomy, King's College Hospital and \\ Medical School, London
}

SUMMARY Studies in the rat with hepatic necrosis induced by carbon tetrachloride showed that the abnormalities in one-stage coagulation tests and the increased catabolism of fibrinogen were similar to those found in man with acute viral or drug-induced hepatic necrosis. Determination of the distribution of the radioactive label shows that excessive deposition was maximal in the liver but also occurred in the spleen. The appearance is delayed by heparin but accelerated by tranexamic acid.

In man, massive hepatic necrosis is frequently complicated by bleeding, which has been thought to be mainly due to a failure of synthesis of clotting factors by the liver (Cook and Sherlock, 1965). However, intravascular coagulation, developing probably as a consequence of the hepatic necrosis, also occurs and may contribute to the diathesis (Rake, Flute, Pannell, and Williams, 1970). This conclusion has been based on three findings: the failure of transfusions to correct the deficiencies, thrombocytopenia despite normal marrow function, and a rapid rate of ${ }^{125} \mathrm{I}$ labelled fibrinogen catabolism which can be decreased by treatment with heparin. Recently we have shown, in two patients with viral and two with drug-induced hepatic necrosis, that early and intensive treatment with heparin as well as fresh frozen plasma can lead to the complete correction of coagulation abnormalities (Rake, Flute, Shilkin, Lewis, Winch, and Williams, 1971).

In man, the actual amount of fibrin formed during the course of the acute hepatic necrosis cannot be measured nor its site of deposition determined. For this purpose we have studied the rat with hepatic necrosis induced by carbon tetrachloride. Measurements have been made of the peripheral utilization of fibrinogen, the occurrence and site of deposition of thrombi, and the effect of an antifibrinolytic agent (tranexamic acid) and an anticoagulant (heparin) on both of these changes.

\section{Methods}

Female virgin rats free of pathogens (including bartonella), obtained from A. E. Tuck and Sons, Received for publication 1 February 1973.
Rayleigh, Essex, were kept isolated in the animal house. Sterile bedding was used, and their diet of purina chow with water ad libitum was also sterilized.

Phenobarbitone was used as a microsomal enzymeinducing agent to accelerate the production of hepatic necrosis by carbon tetrachloride (McLean and McLean, 1966), and was added to the drinking water $(1 \mathrm{~g} /$ litre $)$ for 72 hours preceding each experiment. The carbon tetrachloride was given orally in a dose of $2.5 \mathrm{mg} / \mathrm{kg}$ body weight (diluted $1: 3$ with nut oil), the control groups receiving an equal volume of nut oil. Three series of experiments were undertaken. To avoid repetition the design of these, with the composition of each group of control and test animals, is given with the results of the experiments. Certain groups of animals, also indicated later in the text, were given heparin in a dose sufficient to cause prolongation of the thrombin clotting time to between 84 and $120 \mathrm{sec}$ at three and a half hours after the injection. Other groups were given tranexamic acid in a dose which has been shown, by other workers, to be an effective inhibitor of fibrinolysis in the rat.

In each series, tissue blocks were taken at the time of death from the liver, kidney, spleen, lung, and heart and were examined histologically. The degree of hepatic necrosis was arbitrarily graded 1-3 according to severity. Sections of each organ were also examined for fibrin deposits using phosphotungstic acid-haemotoxylin and Martius-scarlet-blue stains after fixation in formol sublimate.

COAGULATION AND ${ }^{125}$ I-LABELLED

FIBRINOGEN STUDIES

Blood was taken into sequestrene for the estimation of venous haematocrit and into $3.8 \%$ trisodium 
citrate for estimation of plasma fibrinogen, one-stage prothrombin, and thrombin clotting times using the same techniques as in tests on human plasma (Rake et al, 1970, 1971).

Human fibrinogen (Kabi), 3-8 $\mu \mathrm{Ci}$, labelled with ${ }^{125}$ I by the 'jet' iodination method of McFarlane (1963), with a measured clottability of 90 to $95 \%$, was injected into the tail vein of each animal 72 hours before carbon tetrachloride or nut oil administration thus allowing time for equilibration. To measure the rate of disappearance of ${ }^{125} \mathrm{I}$-fibrinogen from the blood, two blood samples $(0.50-0.75 \mathrm{ml}$ each) were collected into sequestrene from each rat, the first by cardiac puncture immediately before the administration of carbon tetrachloride or nut oil, at which stage $35-45 \%$ of the injected radioactivity was recovered. The second was obtained from the inferior vena cava when the animal was killed. Total plasma radioactivity, as counts per second per gram of plasma, was measured in a well-type automatic gamma counter (Nuclear Enterprises). Counts due to free ${ }^{125}$ I were then determined by counting the supernatant after the plasma had been precipitated with an equal volume of $10 \%(w / v)$ trichloracetic acid. This value was subtracted from the total plasma counts; it never exceeded $3 \%$ of the radioactivity. The rate of disappearance of protein-bound radioactivity from the plasma was then expressed as the percentage removed from the plasma by 35 hours, taking the value in the first sample as $100 \%$, thus enabling direct comparison of the results obtained in the different groups of animals studied.

The organ distribution of the administered ${ }^{125} \mathrm{I}$ fibrinogen was also investigated. A proportion of any measurement of organ radioactivity is likely to be due to blood contained within it, and to measure this proportion a plasma marker, namely, ${ }^{131}$ I- labelled albumin, was given at the same time. The injection into the tail vein of $1 \mu \mathrm{Ci}$ of ${ }^{131} \mathrm{I}$-albumin and $3 \mu \mathrm{Ci}$ of ${ }^{125} \mathrm{I}$-fibrinogen was given 72 hours before the administration of carbon tetrachloride or nut oil to allow adequate time for plasma and tissue equilibration. Subsequently the animals were killed with ether at seven-hour intervals up to 35 hours and weighed samples of blood and of each organ (liver, spleen, kidney, heart, and lung) counted for ${ }^{125} \mathrm{I}$ and ${ }^{131} I$ in the automatic gamma counter.

The proportion of ${ }^{125} \mathrm{I}$ in the tissue due to blood contained within it can then be calculated by substitution within the following equation which assumes a similar equilibrium for the distribution of the two isotopes:

$$
{ }^{125} \mathrm{I} \text { tissue }=\frac{{ }^{131} \mathrm{I} \text { tissue } \times{ }^{125} \mathrm{I} \text { blood }}{{ }^{131} \mathrm{I} \text { blood }}
$$

All radioactivity is expressed as total cts/sec/g of blood or tissue. The value obtained was then subtracted from the total ${ }^{125}$ I radioactivity of the organ being considered to find that amount which was not accountable for by blood within that organ. This was then expressed as a percentage of the blood radioactivity in that rat, so as to make possible a comparison between animals and between groups.

\section{Results}

Relevant data concerning the composition of the groups of animals in the three series of experiments, together with the mean values for the animal's weight, haematocrit, and weight of the liver at death, are given in the table.

SERIES I: CHANGES IN COAGULATION The $\mathbf{4 0}$ animals in this series were divided into groups

\begin{tabular}{|c|c|c|c|c|c|}
\hline Series & Group and Number of Animals & Additional Agents & Body Weight (g) & Liver Weight $(g)$ & Haematocrit $(\%)$ \\
\hline $\begin{array}{l}\text { Coagulation } \\
\text { studies }\end{array}$ & $\begin{array}{l}\text { Test } 40 \\
\text { Control } 15\end{array}$ & $\overline{-}$ & $\begin{array}{l}182 \cdot 4( \pm 19 \cdot 3) \\
197 \cdot 7( \pm 32 \cdot 3)\end{array}$ & $\begin{array}{l}8 \cdot 6( \pm 1 \cdot 4) \\
8 \cdot 7( \pm 1 \cdot 4)\end{array}$ & $\begin{array}{l}45 \cdot 6( \pm 4 \cdot 4) \\
43 \cdot 2( \pm 3 \cdot 1)\end{array}$ \\
\hline $\begin{array}{l}2{ }^{125} \text { I-fibrinogen } \\
\text { plasma removal }\end{array}$ & $\begin{array}{l}\text { A Test } 4 \\
\text { Control } 5 \\
\text { B Test } 5 \\
\text { Control } 5 \\
\text { C Test } 5 \\
\text { Control } 5 \\
\text { D Test } 5 \\
\text { Control } 5\end{array}$ & $\begin{array}{l}- \\
\text { Heparin } \\
\text { Heparin } \\
\text { Tranexamic acid } \\
\text { Tranexamic acid } \\
\text { Heparin and tranexamic acid } \\
\text { Heparin and tranexamic acid }\end{array}$ & $\begin{array}{l}184 \cdot 2( \pm 17 \cdot 6) \\
178 \cdot 3( \pm 226) \\
201 \cdot 4( \pm 17 \cdot 6) \\
212.6( \pm 13 \cdot 4) \\
194 \cdot 8( \pm 15 \cdot 4) \\
187.6( \pm 18 \cdot 4) \\
175 \cdot 6( \pm 21 \cdot 2) \\
181.4( \pm 13 \cdot 6)\end{array}$ & $\begin{array}{l}8 \cdot 7( \pm 1 \cdot 2) \\
8 \cdot 5( \pm 1 \cdot 8) \\
8.9( \pm 1 \cdot 3) \\
8.9( \pm 1 \cdot 4) \\
8 \cdot 8( \pm 1 \cdot 7) \\
8 \cdot 8( \pm 1 \cdot 4) \\
8 \cdot 6( \pm 1 \cdot 1) \\
8 \cdot 7( \pm 1 \cdot 6)\end{array}$ & $\begin{array}{l}44 \cdot 0( \pm 1 \cdot 8) \\
44 \cdot 2( \pm 1 \cdot 1) \\
42 \cdot 7( \pm 1 \cdot 0) \\
44 \cdot 6( \pm 2 \cdot 1) \\
43 \cdot 1( \pm 4 \cdot 0) \\
45 \cdot 2( \pm 3 \cdot 1) \\
42 \cdot 8( \pm 4 \cdot 1) \\
44 \cdot 3( \pm 1 \cdot 8)\end{array}$ \\
\hline $\begin{array}{l}{ }^{125} \text { I-fibrinogen } \\
\text { organ distribution }\end{array}$ & $\begin{array}{l}\text { A Test } 15 \\
\text { Control } 5 \\
\text { B Test } 15 \\
\text { Control } 5 \\
\text { C Test } 15 \\
\text { Control } 5 \\
\text { D Test } 15 \\
\text { Control } 5\end{array}$ & $\begin{array}{l}\text { - } \\
\text { Heparin } \\
\text { Heparin } \\
\text { Tranexamic acid } \\
\text { Tranexamic acid } \\
\text { Heparin and tranexamic acid } \\
\text { Heparin and tranexamic acid }\end{array}$ & $\begin{array}{l}182 \cdot 4( \pm 19 \cdot 3) \\
197 \cdot 7( \pm 32 \cdot 3) \\
201 \cdot 2( \pm 13 \cdot 7) \\
221 \cdot 3( \pm 23 \cdot 7) \\
176 \cdot 3( \pm 14 \cdot 1) \\
181 \cdot 2( \pm 13 \cdot 5) \\
188 \cdot 8( \pm 11 \cdot 6) \\
184 \cdot 7( \pm 17 \cdot 6)\end{array}$ & $\begin{array}{l}8.8( \pm 1.4) \\
8.7( \pm 1.4) \\
9.1( \pm 1.0) \\
9.2( \pm 1.4) \\
8.6( \pm 0.9) \\
8.9( \pm 0.6) \\
9.3( \pm 0.3) \\
8.9( \pm 0.6)\end{array}$ & $\begin{array}{l}45.6( \pm 4 \cdot 4) \\
43.2( \pm 3 \cdot 1) \\
43.5( \pm 3 \cdot 1) \\
40.4( \pm 0.6) \\
45.8( \pm 0.3) \\
42.6( \pm 0.6) \\
46.0( \pm 1 \cdot 5) \\
41.8( \pm 1 \cdot 1)\end{array}$ \\
\hline
\end{tabular}

Table Data relating to composition of groups of animals in the three experimental series

${ }^{1}$ Mean values given with 2 SD in brackets. 


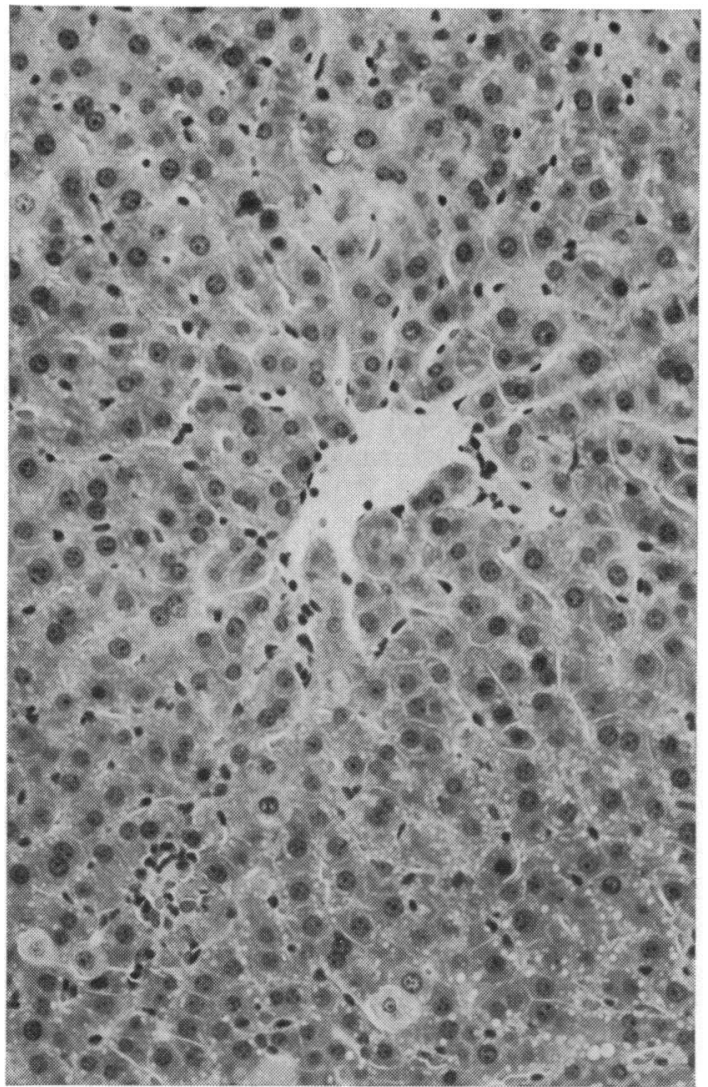

Fig 1

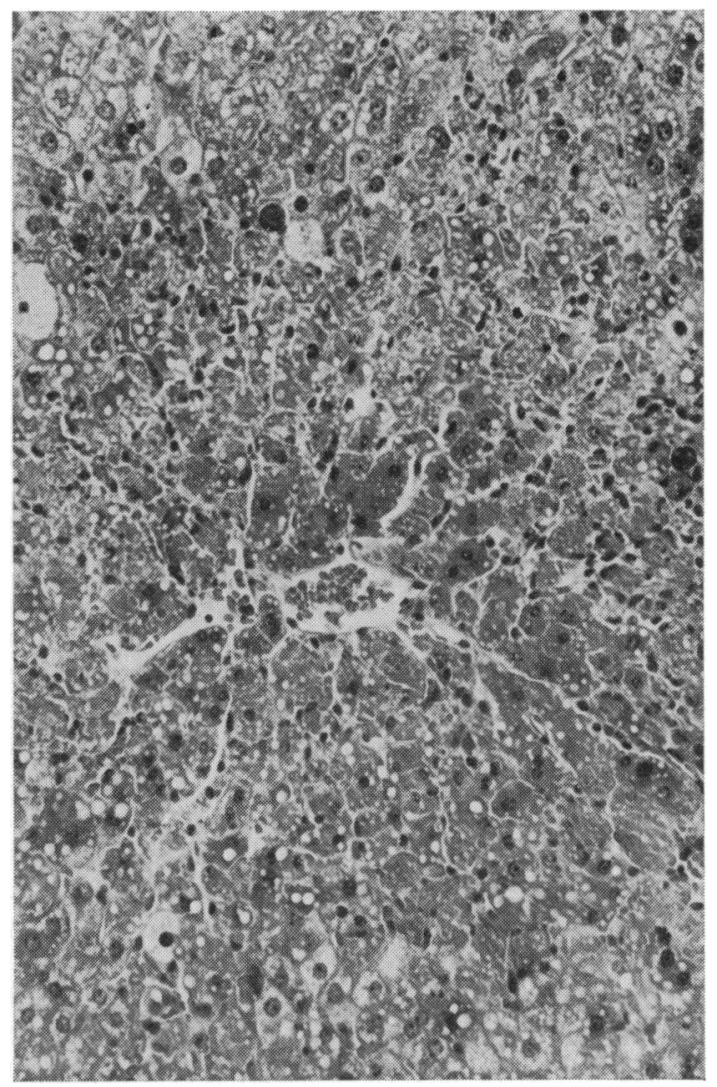

Fig 2

Fig 1 Section showing grade 1 hepatic necrosis (haematoxylin and eosin $\times 225$ ).

Fig 2 Section showing grade 3 hepatic necrosis ( $H \& E \times 225$ ).

of eight, comprising five given carbon tetrachloride and three control animals. One group was killed every seven hours up to 35 hours. None of the control animals showed hepatic necrosis but in the group given carbon tetrachloride it was evident (grade 3) at seven hours and was maximal (grade 3 ) at 28 to 35 hours (figs 1 and 2). In none of the groups was there any macroscopic evidence of bleeding.

The mean prothrombin time in the control animals was 10.9 seconds \pm 1.2 (this and all subsequent data refer to the mean value \pm 2 standard deviations of the mean). In animals given carbon tetrachloride, the prothrombin time was no different from controls at seven hours but in the animals killed at 14 hours it was prolonged to 19.9 seconds \pm 7.5 (fig 3). By 21 hours the prothrombin time had increased to 25.8 seconds $\pm 11 \cdot 1$. Subsequently there was some return to normal although the difference between carbon tetrachloride and control groups at $\mathbf{3 5}$ hours was still significant $(P<0.01)$.
No significant abnormality of the thrombin clotting time was observed until 21 hours after carbon tetrachloride administration. At 35 hours the mean value was 65 seconds \pm 30 , compared to the mean in control animals of 32 seconds \pm 9.4 (fig 3 ), a highly significant difference $(P<0.005)$.

At no time was there a significant reduction in the plasma fibrinogen level (measured gravimetrically). The mean values for the complete control group and for all the animals given carbon tetrachloride were $236.6 \pm 70.6 \mathrm{mg} / 100 \mathrm{ml}$ and $242 \pm 67.6 \mathrm{mg} / 100 \mathrm{ml}$ respectively.

SERIES 2: PLASMA CLEARANCE OF ${ }^{125}$ ILABELLED FIBRINOGEN

The $\mathbf{4 0}$ animals in this study were divided into four groups (A to D) each comprising five carbon tetrachloride and five control animals. The animals in group A received no additional drugs, in group B heparin (450 units/kg body weight), in group C 

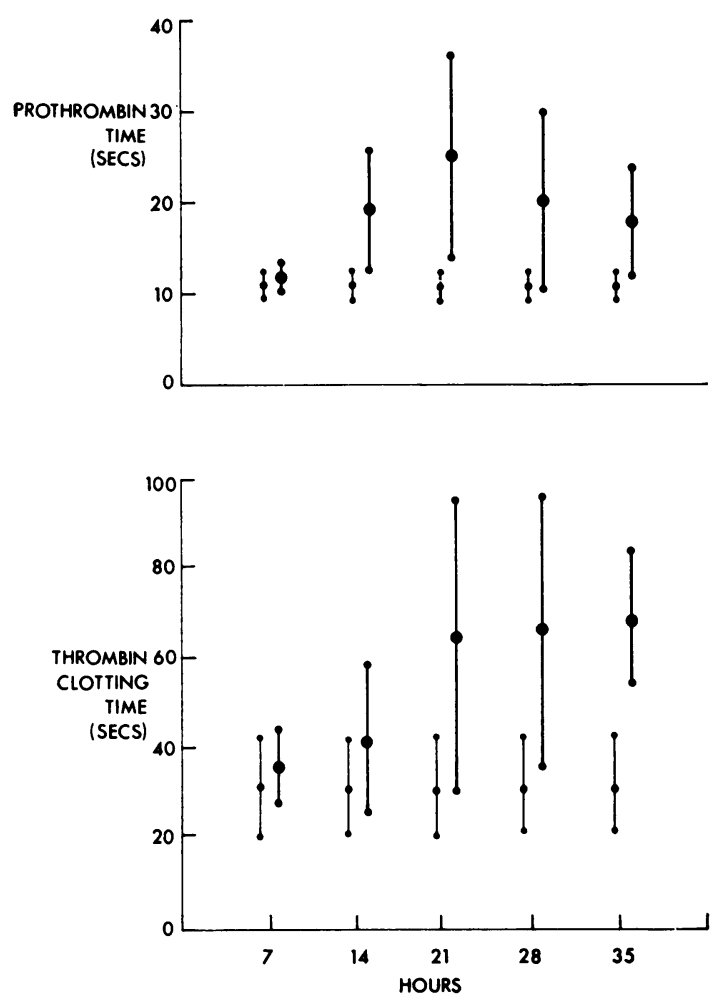

Fig 3 Series 1: the mean prolongation $( \pm 2 S D)$ of the prothrombin and thrombin clotting time for 35 hours after the administration of carbon tetrachloride (control, carbon tetrachloride animals).

tranexamic acid $(0.1 \mathrm{~g} / \mathrm{kg}$ body weight), the animals in group $\mathbf{D}$ receiving both drugs in similar dosage. The drugs were given intraperitoneally immediately before the administration of carbon tetrachloride or nut oil and at intervals of three and a half hours throughout the experiment.

All animals receiving carbon tetrachloride showed severe hepatic necrosis at death. No macroscopic bleeding was observed in group $A$ or in group $C$ in which the animals received tranexamic acid alone, but in groups $B$ and $D$, given heparin and heparin in addition to tranexamic acid, there was evidence of minor bleeding at the site of intraperitoneal injections or cardiac puncture in about a quarter of the animals. The general condition of the animals in group D was worse than in all the other groups; none survived longer than 28 hours.

The percentage of ${ }^{125} \mathrm{I}$ fibrinogen removed from the plasma by 35 hours was the same in control animals whether or not they had received heparin, tranexamic acid, or a combination of both drugs.

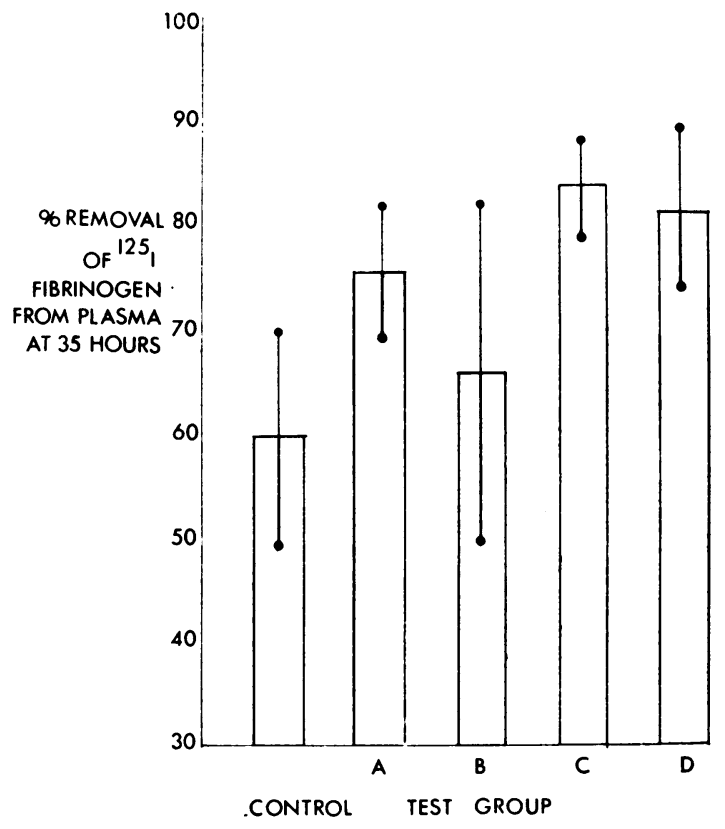

Fig 4 Series 2: the mean $( \pm 2 S D)$ percentage of ${ }^{125}$ I-fibrinogen removed from the plasma at 35 hours in the control group and in groups $A$ carbon tetrachloride alone; $B$ plus heparin; $C$ plus tranexamic acid; $D$ plus both drugs.

All values were pooled giving a mean control value for fibrinogen removal from the plasma of $59.2 \% \pm$ $10 \cdot 5$ (fig 4).

In the test animals given carbon tetrachloride alone there was a significantly greater removal of fibrinogen from the plasma $(75 \% \pm 6)$ during the period of the exper iment than in the control animals $(P<0.01)$. The administration of heparin decreased the rate of removal to $65.5 \% \pm 15.5$ (P 0.05$)$. When tranexamic acid was given the value $83.8 \% \pm 4.2$ was significantly greater than in animals receiving carbon tetrachloride alone $(\mathrm{P}<0.01)$. When heparin and tranexamic acid were given together $81.8 \% \pm 8$ was removed from the plasma. Thus, the increased rate of removal of ${ }^{125}$ I-labelled fibrinogen from the plasma observed in animals with carbon tetrachloride-induced hepatic necrosis is further increased by tranexamic acid and decreased to some extent by heparin although not to control values.

SERIES 3 : ORGAN DISTRIBUTION OF ${ }^{125}$ ILABELLED FIBRINOGEN

The 80 ar imals were divided into four groups as in the series 2 experiments. Each group consisted of 15 animals given carbon tetrachloride and five 
control animals, groups $\mathbf{B}, \mathbf{C}$, and $\mathbf{D}$ receiving in addition either heparin or tranexamic acid alone or both together. It was possible to follow the development of hepatic necrosis as three carbon tetrachloride and one control animal were killed every seven hours up to 35 hours. In group A, hepatic necrosis was first observed at seven hours (grade 1) and was maximal (grade 3) from 28 hours onwards as in the first series of experiments. The addition of heparin in group B appeared to delay the onset of hepatic necrosis, which was not evident until 14 hours and did not reach grade 3 until 35 hours. When tranexamic acid was given alone or in combination with heparin (group $\mathrm{C}$ or group $\mathrm{D}$ ) the necrosis was already present at seven hours and had reached grade 3 at 21 hours, earlier than in the animals receiving carbon tetrachloride alone. Minor bleeding into the peritoneal cavity was seen in about a quarter of all animals receiving heparin, either alone, or in combination with tranexamic acid (groups B and D).

Tissue radioactivity for all the organs in the control animals of the four groups did not differ significantly and the figures have been pooled to give a mean value for the tissue radioactivity in the control group of $8 \cdot 3 \% \pm 6 \cdot 2$ of blood radioactivity. The tissue radioactivity in the liver of animals given carbon tetrachloride was greater than that in the controls at 14 hours and the differences increased to a maximum at 28 hours, reaching over $200 \%$ of the blood level (fig 5). By 35 hours the difference was reduced. The values were similar to those in group B when heparin was given alone but in group $\mathrm{C}$ animals, which received tranexamic acid, the accumulation was delayed and did not reach its maximum $(140 \%$ of blood level) until 35 hours. When heparin and tranexamic acid were administered together (group D) the effect was similar to when tranexamic acid was given alone except that, as in series 2 , all the animals had died by 28 hours and by this time accumulation had reached $85 \%$ of the blood level.

Accumulation of radioactivity was also found in the spleen in all groups of animals receiving carbon tetrachloride as compared with controls. This was less than that found in the liver, the maximum tissue radioactivity being $80 \%$ of blood level at 28 hours (fig 6). In the other organs examined, namely, kidney, lung, and heart, tissue radioactivity greater than that occurring in control animals was not found unless tranexamic acid was given. The excess counts in the kidney in group $\mathrm{C}$, which received this agent alone, had reached $60 \%$ at 21 hours but fell subsequently. In group $\mathrm{D}$, given tranexamic acid together with heparin, all these organs, as well as the liver and spleen already described, showed increased tissue radioactivity when compared to the controls.

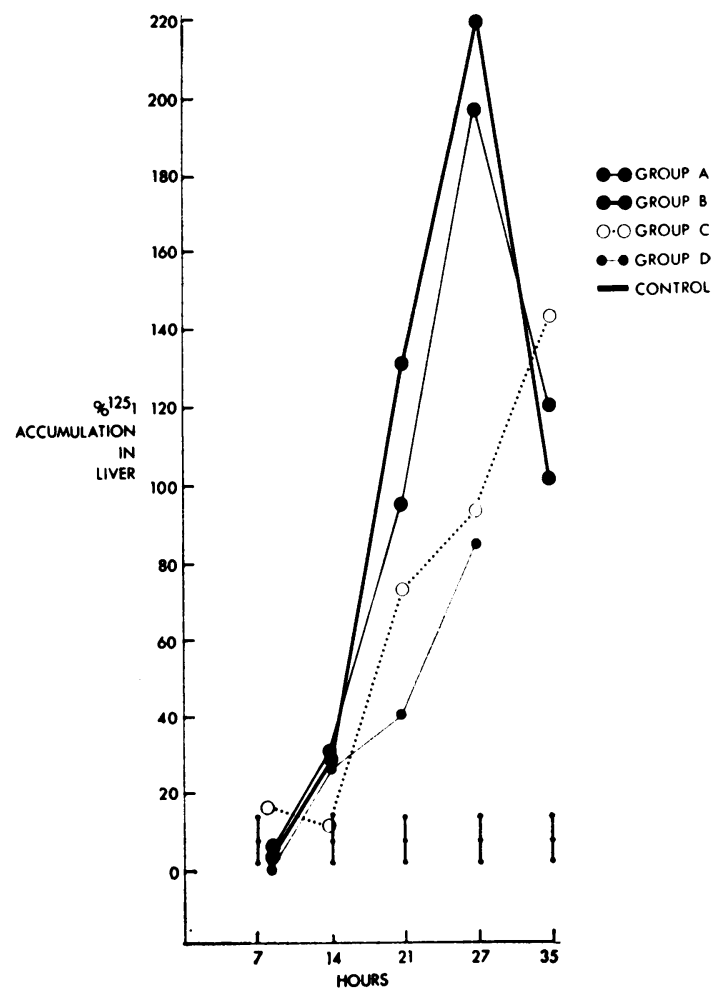

Fig 5 Series 3: the mean accumulation of ${ }^{125} I$ in the liver in controls and in test groups $A, B, C, D$.

\section{Discussion}

The changes in coagulation found in the present studies are very similar to those reported by us in man with fulminant viral or drug-induced hepatic necrosis (Rake et al, 1970). Prothrombin time and thrombin time were prolonged, and the plasma clearance of ${ }^{125} \mathrm{I}$ fibrinogen was rapid. The one-stage prothrombin time is a measure of many clotting proteins with varying rates of plasma clearance and its prolongation can be due to a decrease in synthesis as well as to increased catabolism, or both. Despite the rapid clearance of ${ }^{125}$ I fibrinogen, the plasma fibrinogen as measured gravimetrically remained normal throughout the period of observation and must indicate that hepatic synthesis of fibrinogen was increased despite the necrosis observable on histological examination. This is in agreement with the findings of Ratnoff (1963) and Donaldson, Davies, Dang, and Richmond (1969) in man that the plasma fibrinogen is only decreased in the most severe forms of hepatic necrosis.

The marked prolongation of the thrombin clotting time in the presence of a normal plasma fibrinogen indicates the presence of unusual inhibitory activity 


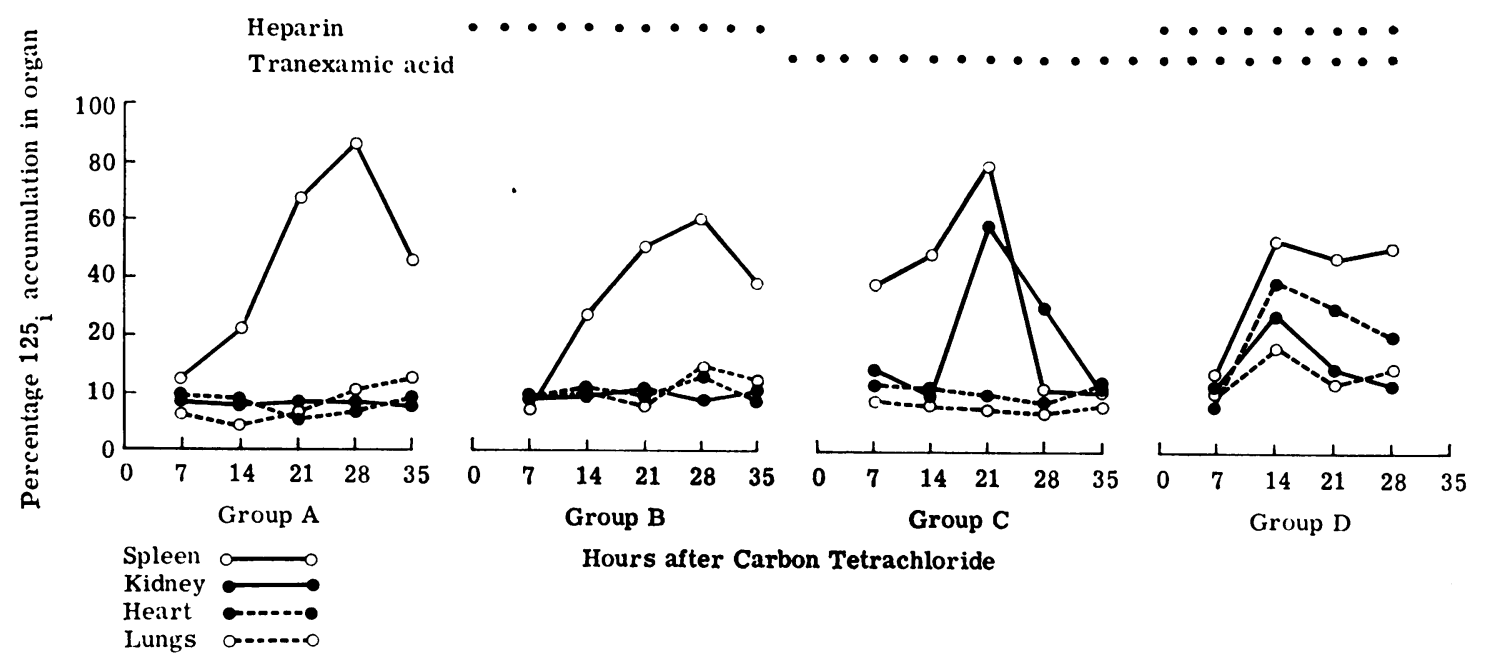

Fig 6 Series 3: the mean accumulation of 125I in spleen, kidney, heart, and lung in the various groups of animals.

in the plasma. This is likely to be due to the presence of fibrin-fibrinogen degradation products in the plasma liberated as a result of a compensatory increase in fibrinolysis. This has been established in man (Rake et al, 1970) but direct measurements of fibrinolysis and fibrin degradation products were not carried out in this study.

Fibrin removal may be accelerated by several mechanisms. Iso-antibody formation by the rat to the human fibrinogen used in those experiments is unlikely, since the whole experiment lasted less than four days, and both the control and test animals were given the same fibrinogen preparation. A major loss of fibrinogen from bleeding is also unlikely, since no animal given carbon tetrachloride alone had macroscopic evidence of bleeding and in the groups given heparin it was of only minor severity. The four other possible routes of fibrinogen loss are difficult to distinguish. In the rabbit (McFarlane, 1963), in man (Regoczi, 1971), and presumably in the rat some $20 \%$ of the total body fibrinogen is extravascular and an increased capillary permeability might account, at least in part, for the observed findings. However, there was no evidence of oedema and liver weights were not significantly different in the test as compared to control animals. Fibrinogen could also have been lost by intravascular coagulation, intravascular fibrinolysis, or by increased removal to reticuloendothelial cells, and the observed effects of heparin, an anticoagulant with little action on the fibrinolytic system, and the effects of tranexamic acid, a potent inhibitor of fibrinolysis with no effect on the coagulation system, provide some further information concerning these possible mechanisms.
Heparin was shown to retard the development of hepatic necrosis and slow the rate of plasma clearance of fibrinogen. However, even when given in doses sufficient to cause minor bleeding in some animals it did not return the plasma clearance completely to normal. This suggests that while local fibrin deposition may contribute to the increased loss of fibrinogen it is not the only cause. Final proof of intravascular coagulation would require the demonstration of fibrin within blood vessels but this was seldom evident by histological techniques although in a few animals in the present studies small numbers of thrombi were seen in the liver sinusoids. However, the fibrin could have been removed by fibrinolysis, which is known to be particularly active in the microcirculation. Indeed some investigators have found difficulty in demonstrating fibrin deposits even in animals being infused with thrombin (Margaretten, Csavossy, and McKay, 1967). The excess of radioactivity found in the liver of the animals with hepatic necrosis could have been attached to fibrinogen, to fibrin, or to fibrin degradation products. The detection of radioactivity in the spleen as well as in the liver suggests that at least a part of it was related to fibrin and fibrinogen degradation products formed in the circulation, and then cleared by the cells of the reticuloendothelial system in these two organs.

The undoubted adverse effects of tranexamic acid administration suggest that an important protection is normally afforded by the fibrinolytic system. Many of the animals given tranexamic acid died before the end of the experiment, whereas the majority of the other animals were showing signs of recovery at this 
time. The administration of tranexamic acid accelerated the appearance of hepatic necrosis, increased the removal of fibrinogen from the plasma, and delayed, though did not prevent, the accumulation of radioactivity in liver and spleen. In addition, excess radioactivity was found for the first time in other organs, namely, the kidney, heart, and lungs. This would be expected if inhibition of fibrinolysis had increased the deposition of fibrin in these peripheral organs. Soluble fibrin complexes with fibrinogen degradation products would also be reduced in amount and this could account for the observed delay in reticuloendothelial cell clearance.

These studies confirm that acute hepatic necrosis is associated with an increased utilization of fibrinogen which may intensify the haemostatic defect and because of the deposition of intravascular fibrin may be responsible for further ischaemic necrosis to the tissues. Heparin administration to the rat, as to man, reduces the increased loss of fibrinogen and may therefore be of value but interference with a normal compensating mechanism of fibrinolysis is clearly contraindicated.
We are grateful to Marjorie Sandiford of the animal house for her ever-willing assistance.

\section{References}

Cook, G. C., and Sherlock, S. (1965). Jaundice and its relation to therapeutic agents. Lancet, 1, 175-179.

Donaldson, G. W. K., Davies, S. H., Darg, A., and Richmond, J. (1969). Coagulation factors in chronic liver disease. J. clin. Path., 22, 199-204.

Margaretten, W. Csavossy, I., and McKay, D. G. (1967). An electron microscopic study of thrombin-induced disseminated intravascular coagulation. Blood, 29, 169-181.

McFarlane, A. S. (1963). In vivo behaviour of $\mathrm{I}^{131}$-fibrinogen. J. clin. Invest., 42, 346-361.

McLean, A. E. M., and McLean, E. K. (1966). The effect of diet and 1,1,1,-trichloro-2,2 bis (p-chlorophenyl) ethane (D.D.T.) on microsomal hydroxylating enzymes and on sensitivity of rats to carbon tetrachloride poisoning. Biochem. J., 100, 564-571.

Rake, M. O., Flute, P. T., Pannell, G., and Williams, R. (1970). Intravascular coagulation in acute liver failure. Lancet, 1, 533-537.

Rake, M. O., Flute, P. T., Shilkin, K. B., Lewis, M. L., Winch, J., and Williams, R. (1971). Early and intensive therapy of intravascular coagulation in acute hepatic necrosis. Lancet, 2, 1215-1218.

Ratnoff, O. D. (1963). Hemostatic mechanisms in liver disease. Med. Clin. N. Amer., 47, 721-736.

Regoeczi, E. (1971). Iodine-labelled fibrinogen: a review. Brit. J. Haemat., 20, 649-663. 